\title{
Coriolus versicolor (Yunzhi) extract attenuates growth of human leukemia xenografts and induces apoptosis through the mitochondrial pathway
}

\author{
CHEONG-YIP HO ${ }^{1}$, CHI-FAI KIM $^{1}$, KWOK-NAM LEUNG ${ }^{2}$, KWOK-PUI FUNG $^{2,3}$, \\ TAK-FU TSE ${ }^{4}$, HELEN CHAN ${ }^{4}$ and CLARA BIK-SAN LAU ${ }^{1}$ \\ ${ }^{1}$ School of Pharmacy, ${ }^{2}$ Department of Biochemistry, ${ }^{3}$ Institute of Chinese Medicine, The Chinese University of \\ Hong Kong, Shatin, New Territories; ${ }^{4}$ Vita Green Health Products Co. Ltd., Suite 1105 , \\ Manning House, 48 Queen's Road Central, Hong Kong, P.R. China
}

Received February 9, 2006; Accepted April 17, 2006

\begin{abstract}
Coriolus versicolor (CV), also called Yunzhi, has been demonstrated to exert anti-tumor effects on various types of cancer cells. Our previous studies have demonstrated that a standardized aqueous ethanol extract prepared from $\mathrm{CV}$ inhibited the proliferation of human leukemia cells via induction of apoptosis. The present study aimed to evaluate the underlying mechanisms of apoptosis through modulation of Bax, Bcl-2 and cytochrome c protein expressions in a human pro-myelocytic leukemia (HL-60) cell line, as well as the potential of the $\mathrm{CV}$ extract as anti-leukemia agent using the athymic mouse xenograft model. Our results demonstrated that the $\mathrm{CV}$ extract dose-dependently suppressed the proliferation of HL-60 cells $\left(\mathrm{IC}_{50}=150.6 \mu \mathrm{g} / \mathrm{ml}\right)$, with increased nucleosome production from apoptotic cells. Expression of pro-apoptotic protein Bax was significantly up-regulated in HL-60 cells treated with the CV extract, especially after 16 and $24 \mathrm{~h}$. Meanwhile, expression of anti-apoptotic protein Bcl-2 was concomitantly down-regulated, as reflected by the increased $\mathrm{Bax} / \mathrm{Bcl}-2$ ratio. The $\mathrm{CV}$ extract markedly, but transiently, promoted the release of cytochrome $\mathrm{c}$ from mitochondria to cytosol after 24-h incubation. In vivo studies in the athymic nude mouse xenograft model also confirmed the growth-inhibitory activity of the CV extract on human leukemia cells. In conclusion, the CV extract attenuated the human
\end{abstract}

Correspondence to: Dr Clara B.-S. Lau, School of Pharmacy, The Chinese University of Hong Kong, Shatin, New Territories, Hong Kong, P.R. China

E-mail: claralau@cuhk.edu.hk

Abbreviations: CV, Coriolus versicolor; PSP, polysaccharopeptide; PSK, protein-bound polysaccharide Krestin; AI, apoptotic index; Cyt c, cytochrome c

Key words: apoptosis, anti-tumor, Bax, Bcl-2, Coriolus versicolor, cytochrome c, leukemia, Yunzhi leukemia cell proliferation in vivo, and in vitro possibly by inducing apoptosis through the mitochondrial pathway. The $\mathrm{CV}$ extract is likely to be valuable for the treatment of some forms of human leukemia.

\section{Introduction}

Global epidemiologic studies have demonstrated that the incidence (3-5\%) and mortality (4-5\%) rates of leukemia still rank high in the worldwide population (1). Significant geographical and racial differences in sex- and age-adjusted incidence and mortality rates of cancers are believed to be affected by a diversity of genetic, environmental and dietary factors. Recently, considerable attention has been devoted to the pathways of programmed cell death and the role of this process in mediating the lethal effects of anti-neoplastic agents in leukemia cells $(2,3)$.

Plant-derived extracts have been historically considered as important alternative remedies for enhancing immune status, prevention and treatment of chronic diseases, including cancers (4). It has been shown that mushroom extracts possess antiviral, anti-tumor and immuno-potentiating activities (5-8). Coriolus versicolor (CV), known as Yunzhi in China, is a mushroom belonging to species of the Homobasidiomycetes class, Polyporaceae family of fungi. Its medicinal value was recorded in the Compendium of Chinese Materia Medica and Shen Non Compendium Medica thousands of years ago in China. Nowadays the therapeutic potentials of CV have been gaining acceptance among patients worldwide $(6,7)$. Among various bioactive components derived from CV, polysaccharopeptide (PSP) is found to be the most prominent in anti-tumor and immunomodulatory activities. PSP is a protein-bound polysaccharide isolated from the deep-layer cultivated mycelia of Coriolus versicolor COV-1 strain (9). The polysaccharide moiety of PSP is a $B(1 \rightarrow 3)$-glucan branching at 4' and 6' positions, and consists of five different sugars including arabinose, glucose, galactose, mannose and xylose, and is rich in aspartic and glutamic acids. The substance has a molecular weight of about 100000 and is highly water-soluble $(7,10)$. Previous studies have reported 
that PSP and PSK (protein-bound polysaccharide Krestin) (11) dose-dependently inhibit the proliferation of leukemia, lymphoma and hepatoma cell lines in vitro (12-14). PSP was also found to stimulate the production of interferon- $\gamma$ and interleukin-2, and increase T-cell proliferation $(10,15)$. In addition, administration of PSP or PSK to nude mice effectively inhibits the growth of human leukemia and hepatoma in vivo $(7,16)$.

Apoptosis is a physiological cell suicide program that is important for the development and maintenance of healthy tissues. Dysregulation of apoptosis is known to occur in cancers, autoimmune diseases and neurodegenerative disorders. Two major apoptotic pathways have been identified thus far, the death receptor-mediated and mitochondria-mediated pathways $(17,18)$. The mitochondriamediated pathway is initiated by cytotoxic drugs, growth factor deprivation or irradiation, and involves the release of cytochrome c (Cyt c) from mitochrondria and activation of caspase-9. The Bcl-2 protein family plays a pivotal role in regulating apoptosis. Pro-apoptotic Bcl-2 family members $\mathrm{Bax}$ and Bak are presumed to form pores or channels by oligomerization in the outer mitochondrial membrane through which Cyt c can be released into the cytosol (17). In contrast, anti-apoptotic Bcl-2 family members such as Bcl-2 and Bcl- $\mathrm{x}_{\mathrm{L}}$ appear to negatively regulate apoptosis by impeding Bax/Bakinduced pore formation and $\mathrm{Cyt} \mathrm{c}$ release in response to death-inducing stimuli, thereby preventing apoptosis $(17,18)$. Previous studies, including ours, have shown that extract of $\mathrm{CV}$ induce apoptosis in breast and cervical tumor cell lines, as well as leukemia and lymphoma cell lines (12,19-21). However, the mechanism implicated in apoptosis induced by the extract of $\mathrm{CV}$ and the effect on leukemia growth in vivo are not yet fully understood.

This study was designed to investigate the mechanisms of apoptosis (through modulation of Bax, $\mathrm{Bcl}-2$ and cytochrome $\mathrm{c}$ protein expressions) induced by a naturally grown Coriolus versicolor ethanol-water standardized extract, on human promyelocytic leukemia cells, and its effect on leukemia growth in athymic mouse xenograft model was examined.

\section{Materials and methods}

Preparation of $C V$ extract. An ethanol-water extract from Coriolus versicolor L. was provided by Vita Green Health Products Company Limited, Hong Kong, in compliance with Good Manufacturing Practice (GMP) standard. The extract was obtained from the fruiting bodies of Coriolus versicolor in the Guangxi province of mainland China. The Coriolus versicolor was authenticated by Professor Xiao-qing Zhang (Mycology expert, Institute of Microbiology Chinese Academy of Sciences, Beijing, P.R. China). Herbarium voucher specimen (no. 2003-2510) was deposited at the museum of the Institute of Chinese Medicine, The Chinese University of Hong Kong. The fruiting bodies were cleaned, crushed and extracted with ethanol-water at proprietary proportions and temperatures, followed by differential precipitation with ethanol. Further processing of specific ethanol fractions led to isolation of the extraction product in powder form (Batch no., Yz03; shelf time, 3 years). The major components of the resulting $\mathrm{CV}$ extract were polysaccharides and triterpenoids, which were approximately $30 \%$ by weight. Plain RPMI-1640 medium (Invitrogen Gibco, NY, USA) was used to dissolve the $\mathrm{CV}$ extract as stock solutions of 3.0 $\mathrm{mg} / \mathrm{ml}$ for $48 \mathrm{~h}$ at room temperature with continuous agitation. Insoluble material was removed by centrifugation and the soluble supernatant was sterilized using a $0.22-\mu \mathrm{m}$ filter, and further diluted with the plain culture medium to the defined concentrations as indicated.

Cell cultures. Human acute promyelocytic leukemia cell line HL-60 was purchased from American Type Culture Collection (ATCC, MD, USA). The cells were grown and maintained in a humidified incubator at $37^{\circ} \mathrm{C}$ and in $5 \% \mathrm{CO}_{2}$ atmosphere. RPMI-1640 medium supplemented with $20 \%$ fetal bovine serum (FBS, Invitrogen Gibco), 100 units/ml penicillin, and $100 \mu \mathrm{g} / \mathrm{ml}$ streptomycin (Invitrogen Gibco) was used for cell cultures of HL-60. After being harvested from culture flasks, the cells were counted using a hemocytometer and cell viability was determined by trypan blue exclusion. Ten thousand cells from log phase cultures were seeded in $100 \mu \mathrm{l}$ of RPMI medium supplemented with $40 \%$ fetal bovine serum per well of 96-well flat-bottom Costar culture plates (Corning Inc., MA, USA). Solutions $(100 \mu \mathrm{l})$ containing $2 \mathrm{X}$ final concentrations of $\mathrm{CV}$ extract in plain culture medium were added per well. Control wells were added with $100 \mu 1$ of plain medium alone. Cells were then incubated with the CV extract for a defined time (see below). Proliferative response and cell death of the $\mathrm{CV}$ extract-treated cells were determined using MTT assay and cell death ELISA, respectively.

MTT assay. The procedure of MTT assay has been described previously (21). Briefly, after incubation of cells with the CV extract for $72 \mathrm{~h}, 30 \mu \mathrm{l}$ of $5 \mathrm{mg} / \mathrm{ml}$ MTT in phosphate-buffered saline (PBS, Invitrogen Gibco) was added to each well and the plate was incubated at $37^{\circ} \mathrm{C}$ for $2 \mathrm{~h}$. The plate was then centrifuged followed by removal of supernatant (culture medium). Dimethylsulfoxide (100 $\mu$ l) (DMSO, Sigma, MO, USA) was then added to each well. Absorbance of the dissolved solution was detected at $540 \mathrm{~nm}$ by a Benchmark microtiter plate reader (Bio-Rad Laboratories, CA, USA). The absorbance of untreated cells was considered as $100 \%$.

Cell death detection. Cell Death Detection ELISA ${ }^{\text {PLus }}$ (Roche Applied Science, Basel, Switzerland) was used to quantify histone-complexed DNA fragments (nucleosomes) in cytoplasm of the apoptotic cells after induction of apoptosis, as described elsewhere (20-22). Briefly, after incubation with the CV extract (at concentrations determined by MTT assay) for 16, 24 and $48 \mathrm{~h}$, the HL-60 cells were pelleted and lysed. The remaining steps were carried out according to the instructions supplied by the manufacturer. The resulting color development, which was proportional to the amount of nucleosomes captured in the antibody sandwich, was measured at $405 \mathrm{~nm}$ (with reference wavelength at $490 \mathrm{~nm}$ ) using a Benchmark microtiter plate reader (Bio-Rad). Results were expressed as the apoptotic index (AI), calculated from the ratio of absorbance of treated (apoptotic) sample to that of the untreated (control) sample.

ELISA of Bax and Bcl-2 protein. Human Bax TiterZyme EIA kit (Assay Designs Inc., MI, USA) and Bcl-2 ELISA kit 


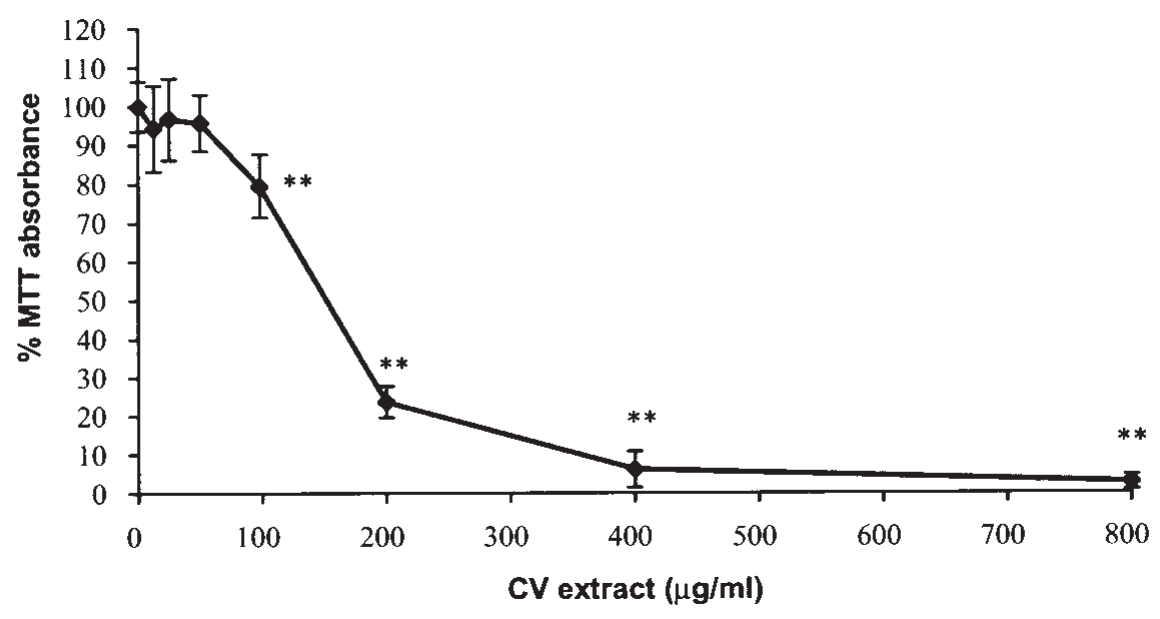

Figure 1. Anti-proliferative effect of CV extract on human leukemia cell line HL-60. Cells were incubated with increasing concentrations (12.5-800 $\mu$ g/ml with 2-fold increase) of the $\mathrm{CV}$ extract in culture medium for $72 \mathrm{~h}$ and the proliferative response was assessed by MTT assay. Results were expressed as the mean $\%$ MTT absorbance (ratio of absorbance in extract-treated well to that of control well x $100 \%$ ) \pm SD of three independent experiments with six wells each. Differences between the treated and control wells were determined by Student's unpaired t-test. ${ }^{* *} \mathrm{p}<0.01$.

(Bender MedSystems GmbH, Vienna, Austria) were used to determine the expression of $\mathrm{Bax}$ and $\mathrm{Bcl}-2$ protein in HL-60 cells respectively. Briefly, after incubation with or without the $\mathrm{CV}$ extract (at the same concentrations in cell death detection) for 16,24 and $48 \mathrm{~h}$, the cells were pelleted and lysed. The remaining steps were carried out according to the instructions supplied by the manufacturer. The final color intensity was proportional to the amount of tested protein in the sample (lysate). The absorbance was measured at $450 \mathrm{~nm}$, and the protein (Bax or Bcl-2) concentration was determined by interpolating from the standard curve. Relative expression of the protein was calculated from the ratio of absorbance of test sample to that of control.

ELISA of cytochrome c. Human Cyt c ELISA kit (Bender MedSystems $\mathrm{GmbH}$ ) was used to determine the release of Cyt c protein from mitochondria in HL-60 cells. Briefly, after incubation with or without the CV extract (at the same concentrations in cell death detection) for 16, 24 and $48 \mathrm{~h}$, the cells were pelleted and selectively lysed. The remaining steps were carried out according to the instructions supplied by the manufacturer. The final color intensity was proportional to the amount of Cyt c protein present in the sample. The absorbance was measured at $450 \mathrm{~nm}$ and Cyt c concentration was determined by interpolating from the standard curve. Relative expression of Cyt c protein was calculated from the ratio of absorbance of test sample to that of control.

In vivo anti-tumor activity. Athymic nude mice (BALB/c nu/nu, with body weight of 20-25 g and aged 6-8 weeks) were kept in autoclaved cage with polyester fiber filters to avoid contact with the pathogens. All the animal diet and tap water were autoclaved before feeding to nude mice ad libitum. Suspension of $1 \times 10^{7}$ of human leukemia HL-60 cells was injected subcutaneously (s.c.) into the dorsal side of nude mice. When palpable tumors (about 100-200 $\mathrm{mm}^{3}$ in volume) arose within 14-18 days after injection, the mice were randomly divided into three groups ( 8 mice per group) and treated with the $\mathrm{CV}$
Table I. Induction of apoptosis by the CV extract on human leukemia HL-60 cells.

\begin{tabular}{lccc}
\hline & \multicolumn{3}{c}{$\mathrm{CV}(\mu \mathrm{g} / \mathrm{ml})$} \\
\cline { 2 - 4 } Time $(\mathrm{h})$ & 0 & 200 & 400 \\
\hline 16 & $1.0 \pm 0.2$ & $\mathbf{2 . 7} \pm \mathbf{0 . 2}$ & $\mathbf{3 . 3} \pm \mathbf{0 . 2}$ \\
24 & $1.0 \pm 0.7$ & $\mathbf{2 . 9} \pm \mathbf{1 . 5}$ & $\mathbf{3 . 6} \pm \mathbf{2 . 0}$ \\
48 & $1.0 \pm 0.0$ & $1.4 \pm 0.1$ & $1.8 \pm 0.1$ \\
\hline
\end{tabular}

Results were expressed as the mean \pm SD values of apoptotic index (AI) in duplicate experiments with three wells each. AI was calculated from the ratio of absorbance reading in $\mathrm{CV}$ extracttreated well to that of control well in duplicate experiments with three wells each. An AI value $\geq 2$ (bold) was considered significant when compared with the untreated control.

extract (100 or $1000 \mathrm{mg} / \mathrm{kg} /$ day in distilled water) or control vehicle (distilled water) by daily gavage. (N.B. $100 \mathrm{mg}$ / $\mathrm{kg}$ /day CV extract is equivalent to the low dose of human recommended daily dosage). Tumor volume was measured by Vernier caliper every 3 days and tumor volumes were calculated according to the formula: tumor volume $\left(\mathrm{mm}^{3}\right)=$ $\mathrm{L} \times \mathrm{W}^{2} \times \pi / 6$, where $\mathrm{L}$ and $\mathrm{W}$ were the major and minor dimensions of the tumor respectively $(\pi=3.1416)$, as described elsewhere (23). After the treatment for 28 days, the nude mice were euthanized and the final body and tumor weights were recorded for calculating the \% ratio of final tumor-tobody weight.

Statistical analysis. Results were expressed as the mean \pm standard deviation (SD). Statistical differences were assessed by the Student's unpaired t-test, with $\mathrm{p}<0.05$ as significant. Results of animal studies were expressed as the mean \pm standard error (SE), and analyzed by two-way ANOVA with 
A

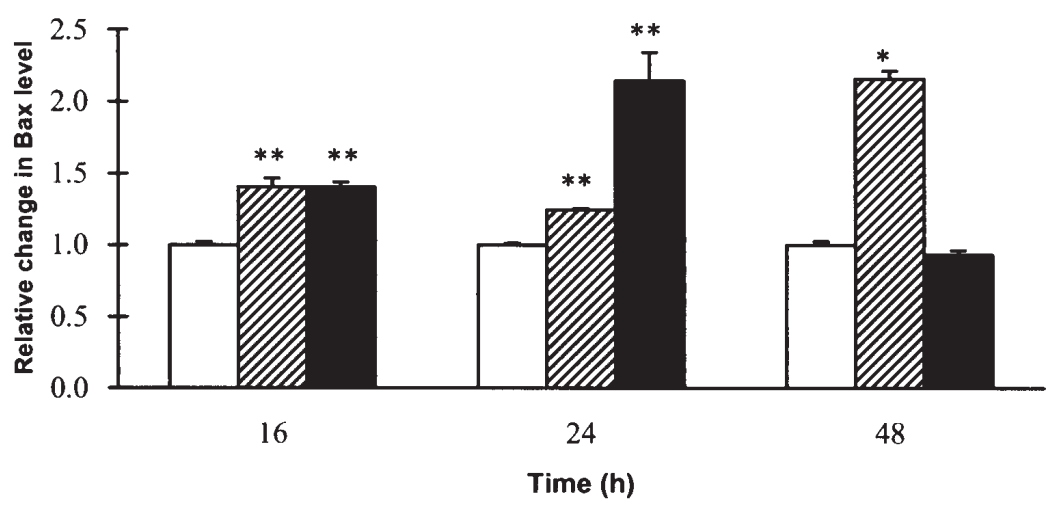

B
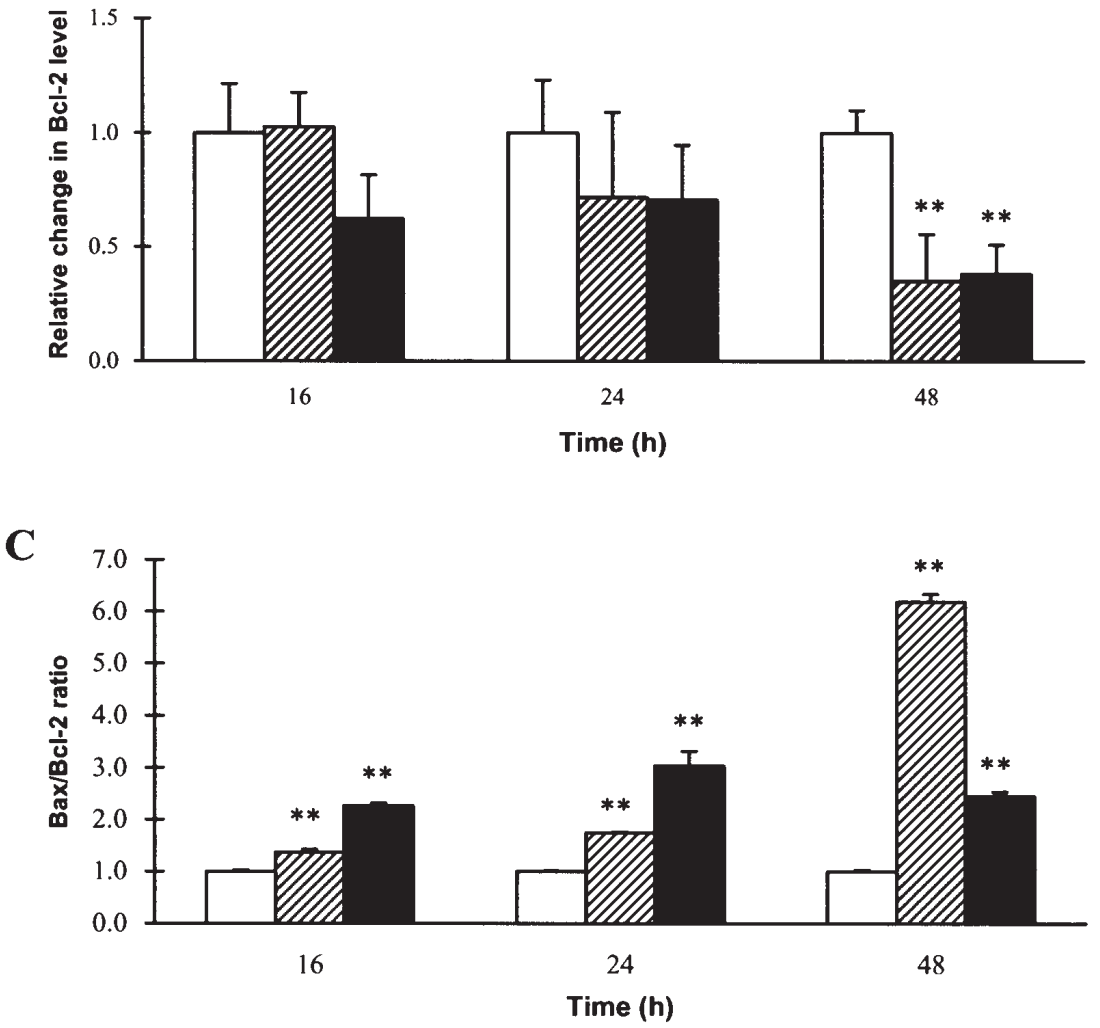

Figure 2. Effects of the CV extract on expression of (A) Bax and (B) Bcl-2 protein, and (C) Bax/Bcl-2 ratio in human leukemia HL-60 cells. Cells were incubated with the CV extract in culture medium at concentrations derived from $\mathrm{IC}_{50}, 200 \mu \mathrm{g} / \mathrm{ml}$ (striped bar) and $400 \mu \mathrm{g} / \mathrm{ml}$ (black bar), or culture medium alone (white bar) for 16, 24 and $48 \mathrm{~h}$. The levels of Bax and Bcl-2 protein were measured by Bax ELISA and Bcl-2 ELISA kits respectively. Results were expressed as the mean $\pm \mathrm{SD}$ in duplicate experiments with three wells each, which was calculated from the ratio of absorbance reading in CV extract-treated well to that of control well. Differences between the treated and control wells were determined by Student's unpaired t-test. ${ }^{* *} \mathrm{p}<0.01$.

Bonferroni's post-tests for multiple comparisons of tumor volumes and by Mann-Whitney $U$ test for \% ratio of final tumor-to-body weight, with $\mathrm{p}<0.05$ as significant. The analyses were performed using the SigmaStat for Windows, version 3.0.1 (SPSS Inc., IL, USA).

\section{Results}

$C V$ extract inhibits the proliferation of human leukemia cells via apoptosis induction in vitro. The CV extract at $100-800 \mu \mathrm{g} /$ $\mathrm{ml}$ was found to significantly suppress the proliferation of human promyelocytic leukemia HL-60 cells in vitro, and the concentration producing $50 \%$ growth inhibition $\left(\mathrm{IC}_{50}\right)$ was
150.6 $\pm 5.7 \mu \mathrm{g} / \mathrm{ml}$ (Fig. 1). The possible mechanism was via induction of apoptosis, as evidenced by the significant increase in nucleosome production (apoptotic index, AI) at 200 and $400 \mu \mathrm{g} / \mathrm{ml}$ of the CV extract after incubation for 16 and $24 \mathrm{~h}$ (Table I).

$C V$ extract up-regulates the expression of Bax with a concomitant down-regulation of Bcl-2 in human leukemia cells in vitro. The Bcl-2 protein family plays a pivotal role in the regulation of apoptosis, and their major site of action is on the regulation of Cyt $\mathrm{c}$ release from mitochondria into the cytosol. The present results showed that the levels of pro-apoptotic protein Bax in HL-60 cells were significantly 


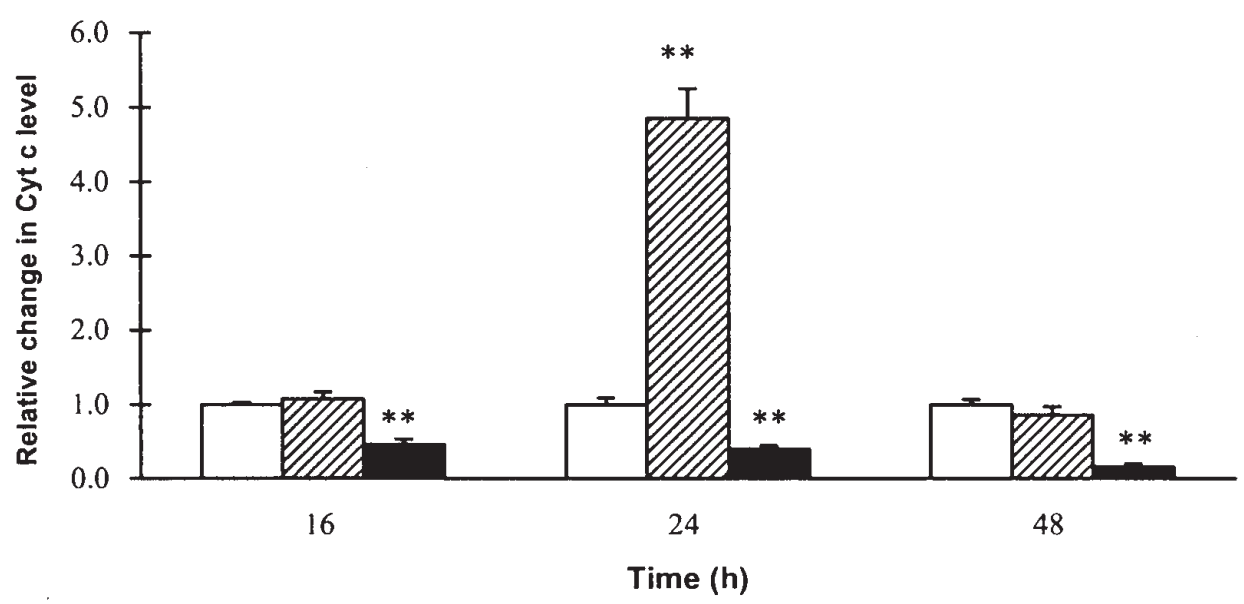

Figure 3. Effects of the CV extract on the release of Cyt c from mitochondria in human leukemia HL-60 cells. Cells were incubated with the CV extract in culture medium at $200 \mu \mathrm{g} / \mathrm{ml}$ (striped bar) and $400 \mu \mathrm{g} / \mathrm{ml}$ (black bar), or culture medium alone (white bar) for 16, 24 and $48 \mathrm{~h}$. The level of Cyt c protein was measured by Cyt c ELISA. Results were expressed as the mean \pm SD in duplicate experiments with three wells each, which was calculated from the ratio of absorbance reading in $\mathrm{CV}$ extract-treated well to that of control well. Differences between the treated and control wells were determined by Student's unpaired t-test. ${ }^{* *} \mathrm{p}<0.01$.

up-regulated by 2.2- and 2.1-fold upon treatment with the $\mathrm{CV}$ extract at both $200 \mu \mathrm{g} / \mathrm{ml}(48 \mathrm{~h})$ and $400 \mu \mathrm{g} / \mathrm{ml}(24 \mathrm{~h})$, respectively (Fig. 2A). In contrast, the levels of anti-apoptotic protein Bcl-2 were markedly decreased by the $\mathrm{CV}$ extract, especially at $48 \mathrm{~h}$ (with a 0.4 -fold reduction for both concentrations, Fig. 2B). It was notable that the increase in ratio of $\mathrm{Bax} / \mathrm{Bcl}-2$ protein level paralleled the up-regulated expression of Bax protein, demonstrating the concomitant reduction of $\mathrm{Bcl}-2$ protein (Fig. 2C).

$C V$ extract promotes the release of cytochrome $c(C y t c)$ in human leukemia cells in vitro. Cyt $\mathrm{c}$ is a mitochondrial protein that is released to the cytosol during apoptosis when the permeability of mitochondrial membrane is disrupted. The CV extract at $200 \mu \mathrm{g} / \mathrm{ml}$ significantly and transiently increased the release of Cyt c from mitochondria 4.9-fold only after $24 \mathrm{~h}$, but not at 16 and $48 \mathrm{~h}$ (Fig. 3). However, the relative level of Cyt c was markedly lowered after incubation with $400 \mu \mathrm{g} / \mathrm{ml}$ of the extract, especially after $24 \mathrm{~h}$ (0.4-fold) and $48 \mathrm{~h}(0.2$ fold).

CV extract suppresses the growth of human leukemia xenografts in athymic mice. CV extract at both doses of 100 and $1000 \mathrm{mg} / \mathrm{kg} /$ day greatly inhibited the growth of subcutaneously transplanted HL-60 cells in athymic mice after 28-day treatment, as measured by both tumor volume (Fig. 4A) and final tumor weight (Fig. 4B). The CV extract at $100 \mathrm{mg} / \mathrm{kg} /$ day seemed slightly more potent than the dose at $1000 \mathrm{mg} / \mathrm{kg} / \mathrm{day}$, as evidenced by the significant suppression of HL-60 growth in terms of tumor volume $(100 \mathrm{mg} / \mathrm{kg} /$ day: from Days $22-28$; $1000 \mathrm{mg} / \mathrm{kg} /$ day: from Days 25-28) and \% ratio of final tumor-to-body weight when compared with the control group (100 mg/kg/day versus control: $11.48 \pm 3.12 \%$ versus $27.04 \pm 2.62 \%, \mathrm{p}<0.01 ; 1000 \mathrm{mg} / \mathrm{kg} /$ day: $24.41 \pm 6.28 \%$ versus $27.04 \pm 2.62 \%, \mathrm{p}>0.05)$. There was no significant difference in the relative tumor volumes and \% ratios of final tumor-tobody weight between the two doses of $\mathrm{CV}$ extract (both $p>0.05)$. No apparent toxicity of the extract was observed during the treatment period, and there was no significant difference between the body weights of control and treated animals.

\section{Discussion}

Our previous studies demonstrated that an ethanol-water extract of a widely used Chinese medicinal herb, Coriolus versicolor in its natural form possesses cytotoxic effects on human leukemia, lymphoma and breast tumor cells via apoptosis induction $(20,21)$. In this study, we investigated the underlying mechanisms of CV extract-induced apoptosis on a human promyelocytic leukemia HL-60 cell line in vitro, and the tumor-suppressing effect of $\mathrm{CV}$ extract in vivo. The present results indicate that the $\mathrm{CV}$ extract significantly inhibited the proliferation of HL-60 cells in a dose- and time-dependent manner with the induction of apoptosis, which was confirmed by the internucleosomal DNA fragmentation (Fig. 1 and Table I). Previous studies have reported that PSP and PSK extracted from cultivated CV exerted anti-proliferative activities on HL-60 cells in a dose-dependent manner via apoptosis induction, but not on normal human peripheral blood lymphocytes $(14,24,25)$. These results were consistent with our present findings that ethanol-water extract of CV selectively suppresses the leukemia growth via apoptosis. Such tumorspecific anti-proliferative activity was further evidenced by our study and other researchers that CV extract significantly potentiates the proliferation of both human peripheral blood and murine spleen lymphocytes $(26,27)$.

Apoptosis is a highly regulated process that involves activation of a cascade of molecular events leading to cell death. Two apoptosis pathways are well known, the death receptor-mediated and mitochondria-mediated pathways, which finally involve the activation of caspases in a common cascade for cleavage of cell death substrates (28). Evidence is emerging that mitochondrion plays a key role in the activation and amplification of caspase cascade via the release of Cyt $\mathrm{c}$ from the mitochondrial intermembrane space, which is considered 

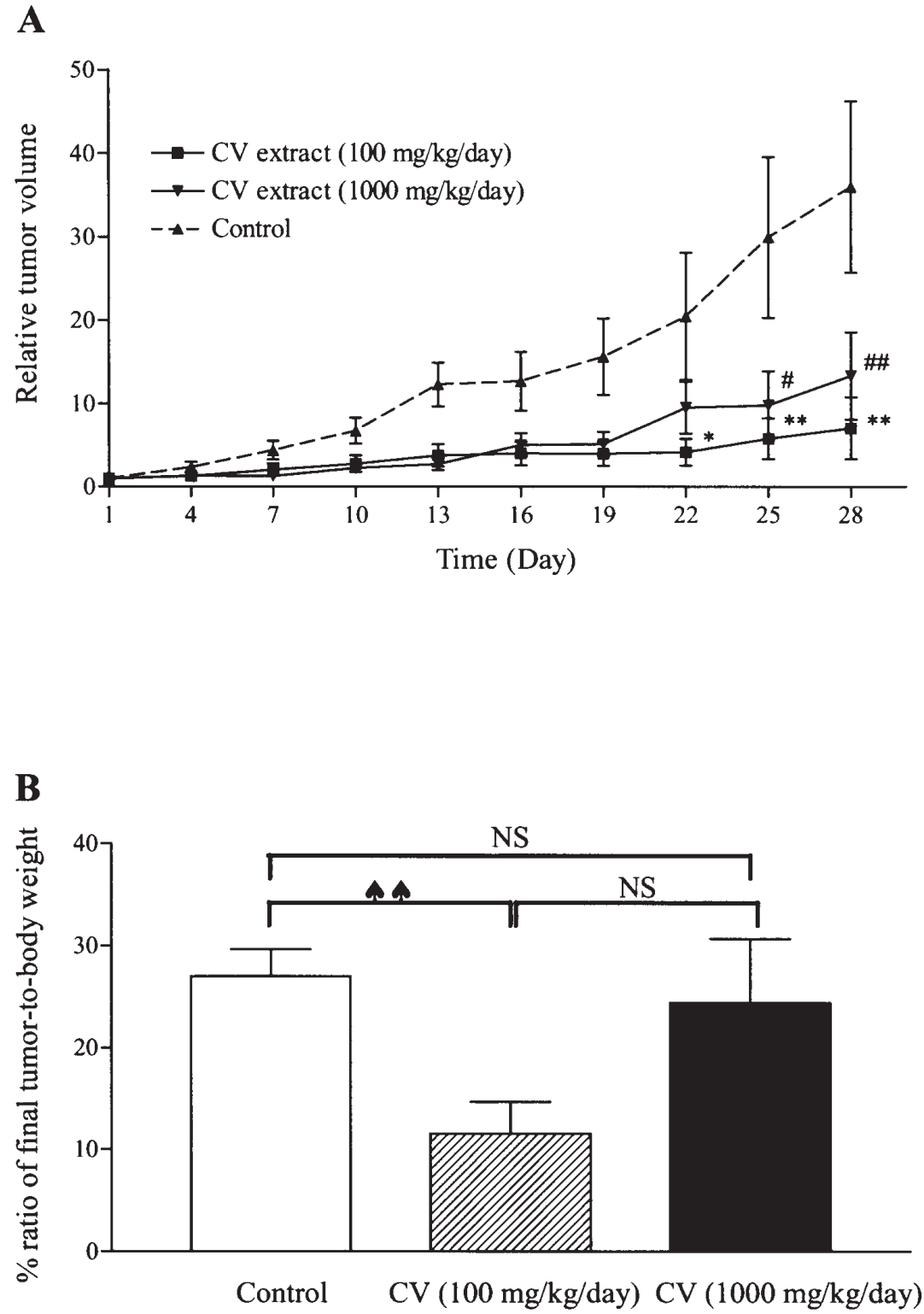

Figure 4. Effect of $\mathrm{CV}$ extract on the growth of human leukemia HL-60 xenografts in athymic mice. A total of $1 \times 10^{7} \mathrm{HL}-60$ cells were injected subcutaneously into the dorsal side of mice. The animals (8 mice per group) were treated with 100 and $1000 \mathrm{mg} / \mathrm{kg} / \mathrm{day}$ of the CV extract, or with vehicle (distilled water) as control for 28 days. (A), For relative tumor volume, results were expressed as the mean \pm SE calculated from the ratio of tumor volume on each test day to that on Day 1 in duplicate experiments. Differences between the relative tumor volume in treated and control groups were determined by two-way ANOVA with Bonferroni post-tests. ${ }^{*} \mathrm{p}<0.05,{ }^{* *} \mathrm{p}<0.01$ for CV extract at $100 \mathrm{mg} / \mathrm{kg} / \mathrm{day} ;{ }^{*} \mathrm{p}<0.05$, ${ }^{* \#} \mathrm{p}<0.01$ for $\mathrm{CV}$ extract at $1000 \mathrm{mg} / \mathrm{kg} / \mathrm{day}$. (B), For \% ratio of final tumor-to-body weight, results were expressed as the mean \pm SE in duplicate experiments. Differences between the treated and control groups were determined by Mann-Whitney rank sum test. ${ }^{\star \star} \mathrm{p}<0.01$; NS, non-significant.

as a pivotal signal that initiates the irreversible events in programmed cell death $(18,29)$. Our results showed that the $\mathrm{CV}$ extract prominently increased the release of Cyt $\mathrm{c}$ from mitochondria in HL-60 cells (Fig. 3), which support our hypothesis that the mitochondria-mediated pathway is the possible mechanism for CV extract-induced apoptosis. On the other hand, the reduction in Cyt c levels in HL-60 cells upon treatment with the $\mathrm{CV}$ extract (at $200 \mu \mathrm{g} / \mathrm{ml}$ after $48 \mathrm{~h}$ and $400 \mu \mathrm{g} / \mathrm{ml}$ after 24 and $48 \mathrm{~h}$ ) might be explained by the degradation of released Cyt $\mathrm{c}$ in late apoptotic and necrotic cells, or its translocation from the interior of dead cells into culture medium following the earlier onset of release (after $24 \mathrm{~h}$ for $200 \mu \mathrm{g} / \mathrm{ml}$ and probably before $16 \mathrm{~h}$ for $400 \mu \mathrm{g} / \mathrm{ml}$ of the CV extract), as suggested by previous studies $(30,31)$.
The Bcl-2 protein family plays a key role in regulating Cyt c release from mitochondria during the early phase of apoptosis $(18,28)$. The $\mathrm{Bcl}-2$ family has more than 10 protein members and are classified into two categories, based on their roles in apoptosis, as anti-apoptotic members such as Bcl-2 and Bcl- $\mathrm{x}_{\mathrm{L}}$ (protect cells from apoptosis), and proapoptotic members such as Bax, Bak and the BH3-only death proteins (trigger or sensitize for apoptosis) (32). Our results demonstrated that the Bax protein level was significantly upregulated in CV extract-treated HL-60 cells at the early onset of apoptosis (16 h, Fig. 2A), preceding the marked release of Cyt c from mitochondria ( 24 h, Fig. 3). This suggested that the Bax protein was responsible for actively inducing the release of Cyt $\mathrm{c}$ upon oligomerization and subsequent 
rupture of outer mitochondrial membrane (18). Meanwhile, the $\mathrm{Bcl}-2$ protein levels were reduced upon treatment with the $\mathrm{CV}$ extract from 16 to $48 \mathrm{~h}$ (despite the lack of statistical significance at early time-points, Fig. 2B). Such reduction in Bcl-2 levels was concomitant with the increase in Bax levels, as demonstrated by the parallel increase in $\mathrm{Bax} / \mathrm{Bcl}-2$ ratio (Fig. 2C). Since it is believed that the ratio between proapoptotic and anti-apoptotic proteins determines whether cells will undergo apoptosis or not, the present findings reflected that the $\mathrm{CV}$ extract might disturb the $\mathrm{Bax} / \mathrm{Bcl}-2$ ratio and hence trigger the mitochondrial Cyt $\mathrm{c}$ release for apoptosis of HL-60 cells. However, direct physiological interaction between pro-apoptotic and anti-apoptotic Bcl-2 family proteins in the mitochondrial membrane has not been demonstrated beyond doubt, hence other indirect models such as competition for mitochondrial targets have to be considered $(17,32)$. In addition, there are also many other indicators which are commonly used to support the involvement of the mitochondrial pathway, such as the induction of mitochondrial membrane depolarization, and the activation of pro-caspase 9 to caspase 9 etc. Further studies will have to be conducted in order to demonstrate whether the CV extract can also induce apoptosis through the extrinsic pathway - i.e., via the death-receptor pathway.

The present in vivo results confirmed the growth-inhibitory effect of CV extract on human leukemia xenografts in athymic nude mice (Fig. 4). Throughout the 28 days of treatment, the $\mathrm{CV}$ extract at $100 \mathrm{mg} / \mathrm{kg} /$ day seemed slightly more efficacious in tumor suppression than at $1000 \mathrm{mg} / \mathrm{kg} /$ day, as demonstrated by the earlier onset of significant tumor growth inhibition (Fig. 4A). The ratio of final tumor-to-body weight for the lower dose of CV extract was significantly reduced when compared with the control; however, no significant difference was found between the higher dose of $\mathrm{CV}$ extract and the control group (Fig. 4B). It should be noted that the lack of significant difference between the two doses of $\mathrm{CV}$ extract in terms of relative tumor volume and \% ratio of final tumor-to-body weight implied the absence of obvious dose-dependent tumorsuppressing effect on HL-60 xenografts. Such a phenomenon might be due to the small number of animals in the experiment, which introduced intra-assay variations. In addition, the combined results of duplicate experiments also produce inter-assay deviations. The mice all survived the treatment period without apparent toxicity. No significant difference in body weight between the treated and control groups was observed, although the control mice seemed less active because of larger tumor burden.

In conclusion, our study showed that the CV extract induced apoptosis of human promyelocytic leukemia HL-60 cells through the mitochondria-mediated pathway, with marked increase in Bax levels and concomitant reduction in $\mathrm{Bcl}-2$ levels, as well as the release of Cyt $\mathrm{c}$ from mitochondria to cytosol. In addition, the $\mathrm{CV}$ extract significantly attenuated the growth of human leukemia xenografts in athymic mice in vivo. These findings reflect that the $\mathrm{CV}$ extract has potential therapeutic value for treatment of some forms of leukemia.

\section{Acknowledgements}

This study was supported by the Innovation and Technology Fund (ITF) matching grant, of Innovation and Technology
Commission and Vita Green Health Products Company Ltd., Hong Kong. The authors would like to thank Professor Xiaoqing Zhang, a mycology expert (Systematic Mycology and Lichenology Laboratory, Institute of Microbiology Chinese Academy of Sciences, Beijing, P.R. China) who examined and authenticated the Coriolus versicolor sample used.

\section{References}

1. Jemal A, Tiwari RC, Murray T, Ghafoor A, Samuels A, Ward E, Feuer EJ and Thun MJ: American Cancer Society. Cancer statistics, 2004. CA Cancer J Clin 54: 8-29, 2004.

2. Friesen C, Fulda $S$ and Debatin KM: Cytotoxic drugs and the CD95 pathway. Leukemia 13: 1854-1858, 1999.

3. Solary E, Bettaieb A, Dubrez-Daloz L and Corcos L: Mitochondria as a target for inducing death of malignant hematopoietic cells. Leuk Lymphoma 44: 563-574, 2003.

4. Spencer JW: Essential issues in complementary/alternative medicine. In: Complementary/Alternative Medicine, An Evidence-based Approach. Spencer JW and Jacobs JJ (eds). Mosby, St. Louis, pp3-36, 1999.

5. Borchers AT, Stern JS, Hackman RM, Keen CL and Gershwin ME: Mushrooms, tumors and immunity. Proc Soc Exp Biol Med 221: 281-293, 1999.

6. Kidd PM: The use of mushroom glucans and proteoglycans in cancer treatment. Altern Med Rev 5: 4-27, 2000.

7. Ng TB: A review of research on the protein-bound polysaccharide (polysaccharopeptide, PSP) from the Mushroom Coriolus versicolor (Basidiomycetes: Polyporaceae). Gen Pharmacol 30: $1-4,1998$.

8. Ooi VE and Liu F: A review of pharmacological activities of mushroom polysaccharides. Int J Med Mushrooms 1: 195-206, 1999.

9. Yang MM, Chen Z and Kwok JS: The anti-tumor effect of a small polypeptide from Coriolus versicolor (SPCV). Am J Chin Med 20: 221-232, 1992.

10. Wang HX, Ng TB, Liu WK, Ooi VE and Chang ST: Polysaccharide-peptide complexes from the cultured mycelia of the mushroom Coriolus versicolor and their culture medium activate mouse lymphocytes and macrophages. Int J Biochem Cell Biol 28: 601-607, 1996.

11. Sakagami H, Aoki T, Simpson A and Tanuma S: Induction of immunopotentiation activity by a protein-bound polysaccharide, PSK (review). Anticancer Res 11: 993-999, 1991.

12. Chow LW, Lo CS, Loo WT, Hu XC and Sham JS: Polysaccharide peptide mediates apoptosis by up-regulating p21 gene and down-regulating cyclin D1 gene. Am J Chin Med 31: 1-9, 2003.

13. Dong Y, Yang MP and Kwan CY: In vitro inhibition of proliferation of HL-60 cells by tetrandrine and Coriolus versicolor peptide derived from Chinese medicinal herbs. Life Sci 60: 135-140, 1997.

14. Hsieh TC, Kunicki J, Darzynkiewicz Z and Wu JM: Effects of extracts of Coriolus versicolor (I'm-Yunity) on cell-cycle progression and expression of interleukins- 1 beta, -6 and -8 in promyelocytic HL-60 leukemic cells and mitogenically stimulated and non-stimulated human lymphocytes. J Altern Complement Med 8: 591-602, 2002.

15. Qian ZM, Xu MF and Tang PL: Polysaccharide peptide (PSP) restores immunosuppression induced by cyclophosphamide in rats. Am J Chin Med 25: 27-35, 1997.

16. Dong Y, Kwan CY, Chen ZN and Yang MP: Anti-tumor effects of a refined polysaccharide peptide fraction isolated from Coriolus versicolor in vitro and in vivo studies. Res Commun Mol Pathol Pharmacol 92: 140-148, 1996.

17. Kirkin V, Joos S and Zornig M: The role of Bcl-2 family members in tumorigenesis. Biochim Biophys Acta 1644: 229-249, 2004.

18. Borner C: The Bcl-2 protein family: sensors and check-points for life-or-death decisions. Mol Immunol 39: 615-647, 2003.

19. Han B, Toyomasu T and Shinozawa T: Induction of apoptosis by Coprinus disseminatus mycelial culture broth extract in human cervical cancer cells. Cell Struct Funct 24: 209-215, 1999.

20. Ho CY, Kim CF, Leung KN, Fung KP, Tse TF, Chan H and Lau CBS: Differential anti-tumor activity of Coriolus versicolor (Yunzhi) extract through p53- and/or Bcl-2-dependent apoptotic pathway in human breast cancer cells. Cancer Biol Ther 4: 638-644, 2005. 
21. Lau CBS, Ho CY, Kim CF, Leung KN, Fung KP, Tse TF, Chan HHL and Chow MSS: Cytotoxic activities of Coriolus versicolor (Yunzhi) extract on human leukemia and lymphoma cells by induction of apoptosis. Life Sci 75: 797-808, 2004.

22. Sellers WR and Fisher DE: Apoptosis and cancer drug targeting. J Clin Invest 104: 1655-1661, 1999.

23. Clarke R: Issues in experimental design and end-point analysis in the study of experimental cytotoxic agents in vivo in breast cancer and other models. Breast Cancer Res Treat 46: 255-278, 1997.

24. Yang X, Sit WH, Chan DK and Wan JM: The cell death process of the anticancer agent polysaccharide-peptide (PSP) in human promyelocytic leukemic HL-60 cells. Oncol Rep 13: 1201-1210, 2005.

25. Zeng F, Hon CC, Sit WH, Chow KY, Hui RK, Law IK, Ng VW, Yang XT, Leung FC and Wan JM: Molecular characterization of Coriolus versicolor PSP-induced apoptosis in human promyelocytic leukemic HL-60 cells using cDNA microarray. Int J Oncol 27: 513-523, 2005.

26. Ho CY, Lau CBS, Kim CF, Leung KN, Fung KP, Tse TF, Chan HHL and Chow MSS: Differential effect of Coriolus versicolor (Yunzhi) extract on cytokine production by murine lymphocytes in vitro. Int Immunopharmacol 4: 1549-1557, 2004.
27. Wong CK, Bao YX, Wong EL, Leung PC, Fung KP and Lam CW Immunomodulatory activities of Yunzhi and Danshen in posttreatment breast cancer patients. Am J Chin Med 33: 381-395, 2005.

28. Strasser A, O'Connor L and Dixit VM: Apoptosis signaling. Ann Rev Biochem 69: 217-245, 2000.

29. Martinou JC, Desagher S and Antonsson B: Cytochrome c release from mitochondria: all or nothing. Nat Cell Biol 2: E41-E43, 2000.

30. Bobba A, Atlante A, Giannattasio S, Sgaramella G, Calissano P and Marra E: Early release and subsequent caspase-mediated degradation of cytochrome $\mathrm{c}$ in apoptotic cerebellar granule cells. FEBS Lett 457: 126-130, 1999.

31. Jemmerson R, La Plante B and Treeful A: Release of intact, monomeric cytochrome $\mathrm{c}$ from apoptotic and necrotic cells. Cell Death Differ 9: 538-548, 2002.

32. Cory S and Adams JM: The Bcl-2 family: regulators of the cellular life-or-death switch. Nat Rev Cancer 2: 647-656, 2002. 